\title{
CORRELATION BETWEEN UNCONFINED COMPRESSIVE STRENGTH AND INDIRECT TENSILE STRENGTH FOR JOINTED ROCKS
}

\author{
N.Kabilan ${ }^{1}$, M.Muttharam ${ }^{2}$ \\ ${ }^{I}$ Former PG Student, Department of Civil Engineering, CEG Anna University, Tamil Nadu, India \\ ${ }^{2}$ Professor, Department of Civil Engineering, CEG Anna University, Tamil Nadu, India \\ +919840153098, kabilankp@yahoo.com
}

\begin{abstract}
Design Process in rock is very tedious because of its different nature compared to other engineering materials due to its distinct joint conditions like orientation, roughness, location \& frequency affect the strength of jointed rock. Experimenting indirect tensile strength is very fast comparing with unconfined compressive strength. Material was created using plaster of Paris and water to simulate as jointed rocks. Three joint conditions were considered for evaluating the unconfined compressive strength using indirect tensile strength (joint orientation, joint roughness and number of joints). The model was prepared joint roughness using galvanized sheet, saw toothed blade and thin layer of bentonite clay in between the joints. By using multiple linear regression analysis unconfined compressive strength was predicted using indirect tensile strength. There is less number of research work carried out using jointed rocks for correlating unconfined compressive strength with indirect tensile strength. The present investigation was carried out to develop a relation between indirect tension and uniaxial compressive strength.
\end{abstract}

Keywords: Unconfined Compressive Strength, indirect tensile strength, Joint Conditions and Correlation.

\section{INTRODUCTION}

Rock engineers commonly use the unconfined compressive strength [UCS] of rocks for designing the underground structures. The standardized ASTM and ISRM are used to measure the rock strength generally [6-9]. Above method to determine the compressive strength (UCS) is time consuming and expensive. Field tests such as point load index $\left[\mathrm{I}_{50}\right]$ and indirect tension strength are used to predict the UCS indirectly. These tests are preferred due to its simple work in sample preparation and easy to perform the test within less duration. The Present work is to create an relationship for unconfined compressive strength $\&$ indirect tension strength for jointed rocks. To simulate jointed rocks, mixture of plaster of paris and water was used as model materials. Vekinis et al. [13] says that plaster of paris is a brittle, porous solid, easy to shape, which has potential as a model material for the study of brittle, porous, solids such as ceramics, rock and cement. The three joint conditions were considered and they are smooth joints, rough joints and join to fill with gauge. To simulate these conditions in model specimen thin galvanized sheet, was toothed blade and thin layer of bentonite clay in between the joints were used. The data was analyzed statistically to determine the degree of correlation and the variability of results.

\section{PREVIOUS INVESTIGATIONS}

Many researchers have been conducted to show that UCS is related to point load index and indirect tension test [1-3], [10-12]. According Farah [1], indirect tensile strength has a better correlation with UCS then that of point load strength. He conducted a comprehensive study to obtain correlations between UCS and physical properties of weathered Ocala limestone. Kahraman et al. [3] proposed a study on compressive and tensile strength of different types of rocks. Altindag and Guney [4] conducted a wide study on different types of rocks to bring out strong correlation.

Table -1: Correlation between UCS and BIS

\begin{tabular}{|l|l|l|l|}
\hline References & Correlation & $\mathrm{R}$ of $\mathrm{R}^{2}$ & Rock Type \\
\hline Farah $(2011)$ & $\begin{array}{l}\mathrm{UCS}(\mathrm{psi})=5.11 * \mathrm{BTS}- \\
133.86\end{array}$ & $\mathrm{R}^{2}=0.68$ & Weathered limestone \\
\hline Tahiretal $(2011)$ & $\mathrm{UCS}(\mathrm{MPa})=7.53 * \mathrm{BTS}$ & $\mathrm{R}^{2}=0.44$ & Limestone samples \\
\hline Kahraman et al. $(2012)$ & $\mathrm{UCS}(\mathrm{MPa})=10.61 *$ BTS & $\mathrm{R}^{2}=0.5$ & $\begin{array}{l}\text { Different types of rock } \\
\text { including limestone }\end{array}$ \\
\hline $\begin{array}{l}\text { Altindag and Guney } \\
(2010)\end{array}$ & $\mathrm{UCS}(\mathrm{MPa})=12.38 * \mathrm{BTS}^{1.025}$ & $\mathrm{R}=0.39$ & $\begin{array}{l}\text { Different types of rock } \\
\text { including limestone }\end{array}$ \\
\hline
\end{tabular}




\section{RESEARCH METHODOLOGY}

\subsection{Sample Preparation}

To simulate jointed rocks, mixture of plaster of Paris and water was used as a model material. Various moulds for different orientation of joint with respect to major principal stress viz. $0^{\circ}, 10^{\circ} 30^{\circ}, 45^{\circ}, 60^{\circ}, 90^{\circ}$ were prepared separately. The inner diameter of the mould is $50 \mathrm{~mm}$ and height is $100 \mathrm{~mm}$. Required amount of water was added to achieve a water content of $38 \%$, which is the optimum moisture content to achieve maximum UCC for intact specimen.

\subsection{Making Joints In Specimens}

To simulate jointed rocks, mixture of plaster of Paris and water used as a model material. Various moulds for different orientation of joint with respect to major principal stress viz. $0^{0}, 30^{\circ}, 45^{\circ}, 60^{\circ}$ and $90^{\circ}$ were prepared separately.

Samples were casted in the mould using kneading compaction technique. Proper care was taken to expel any air voids etc. After casting, required joint orientation was created by cutting along pre-existing joints in the prepared equipment used to make a Joints for different orientation In this three joint condition were considered and they are smooth joints, rough joint, and joint filled with fines.

\subsection{Test Procedures}

The unconfined compressive strength was determined as per International society for rock mechanics [ISRM]. The jointed rock samples were prepared with smooth joint, rough joint and joint filled with gauge. And the samples had length to diameter ratio of 2 and met the tolerance limits of 2 to 2.5 with flat, smooth and parallel ends cut perpendicularly to the cylinder axis. The unconfined compressive testing machine used for conducting the experiment is shown in Figure 1. The jointed rock samples were prepared with smooth joint, rough joint and joint filled with a gauge. For each joint condition three trail specimens were tested.

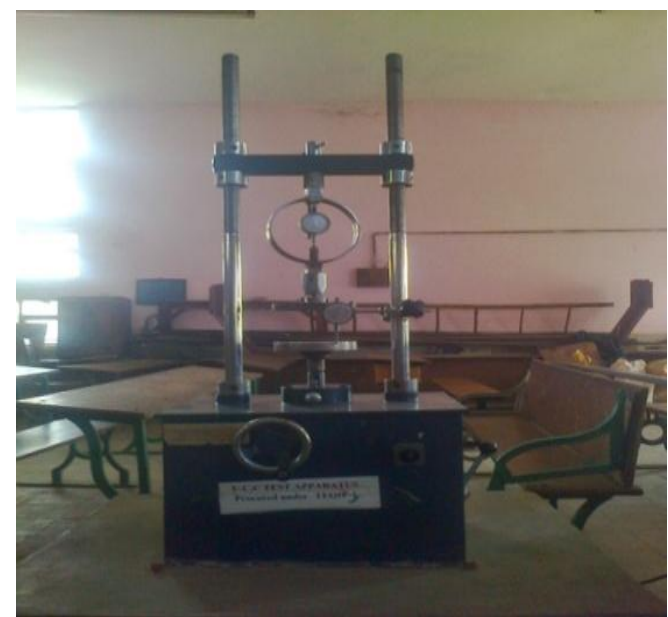

Fig -1: Unconfined Compressive Strength Apparatus

The indirect tension test was performed in accordance with the procedure standardized by ISRM. The indirect tension test is an attractive alternative to the UCS because it can provide similar data at a lower cost and quicker. The jointed rock samples were prepared with smooth joint, rough joint and joint filled with gouge. And the prepared samples were tested through indirect tension testing machine [Figure 2].

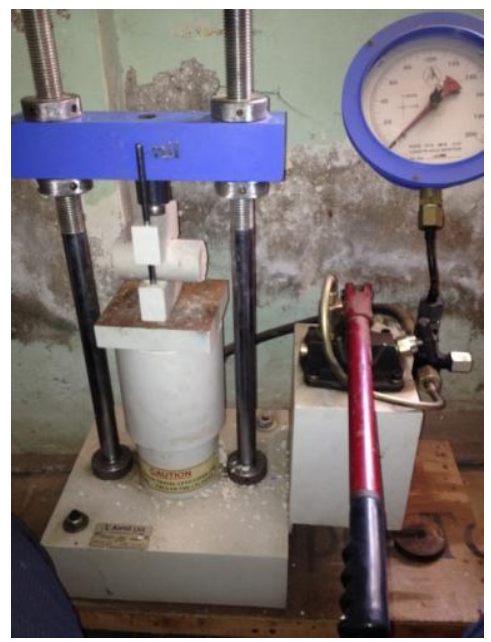

Fig -2: Indirect Tension Testing Machine

\subsection{Regression Analysis by SPSS Software}

The variability of results for each test and joint conditions was evaluated by determining the coefficient of variation. The results of the uniaxial compression test were correlated with tension strength test results and joint conditions using the method of multiple regression analysis. The equations of the best fit curves, the $95 \%$ confidence limits, and the correlation coefficients $\left(\mathrm{R}^{2}\right)$ were determined for each case. These equations could be used to predict the uniaxial compressive strength from the results of the Indirect tension strength and joint condition.

\section{TEST RESULTS AND DISCUSSION}

\subsection{Analysis of Unconfined Compressive Strength}

\section{Results}

Variation of UCS with joint orientation for different joint condition is plotted in Figure 3 and Figure 4

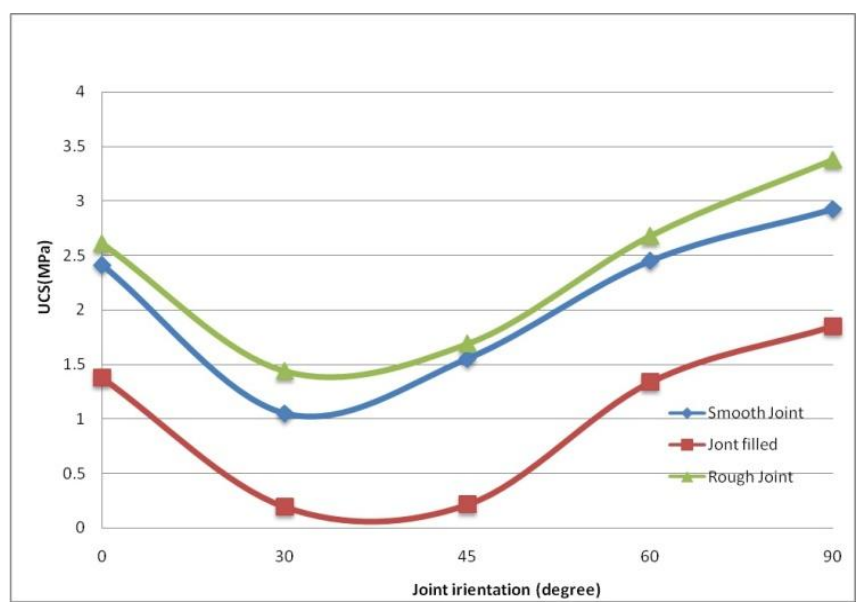

Fig -3: Relation between UCS and Joint Orientation for Single Jointed Specimen 


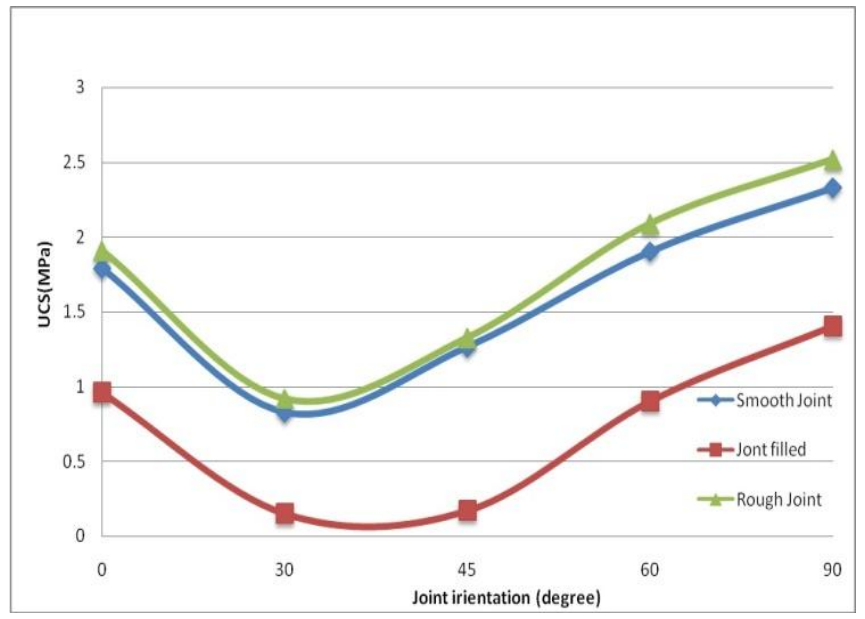

Fig -4: Relation between UCS and Joint Orientation for Double Jointed Specimen

For the joint oriented at $30^{\circ}$, the specimen showed lesser value of UCS compared to other join orientation. This may be due to the fact that the sample tends to fail along the weaker plane, in the present case the existing joint orientation which is the weakest plane, is unfavorable orientation which makes the sample to offer less resistance. On comparing the UCS of smooth joint with that of clay filled joint, the UCS values gets reduced about $83.1 \%$ for $30^{\circ}$ orientation, $86.22 \%$ for $45^{\circ}$ orientation, $49.9 \%$ for $60^{\circ}$ orientation and $36.22 \%$ for $90^{\circ}$ orientation. This may be due to the reduction in friction of joint because of the plastic nature of clay filled in joint.

\subsection{Analysis of Indirect Tension Results}

Relationship between tensile strength (Indirect Tension) and joint orientation for different joint condition is plotted in Figure 5 and Figure 6

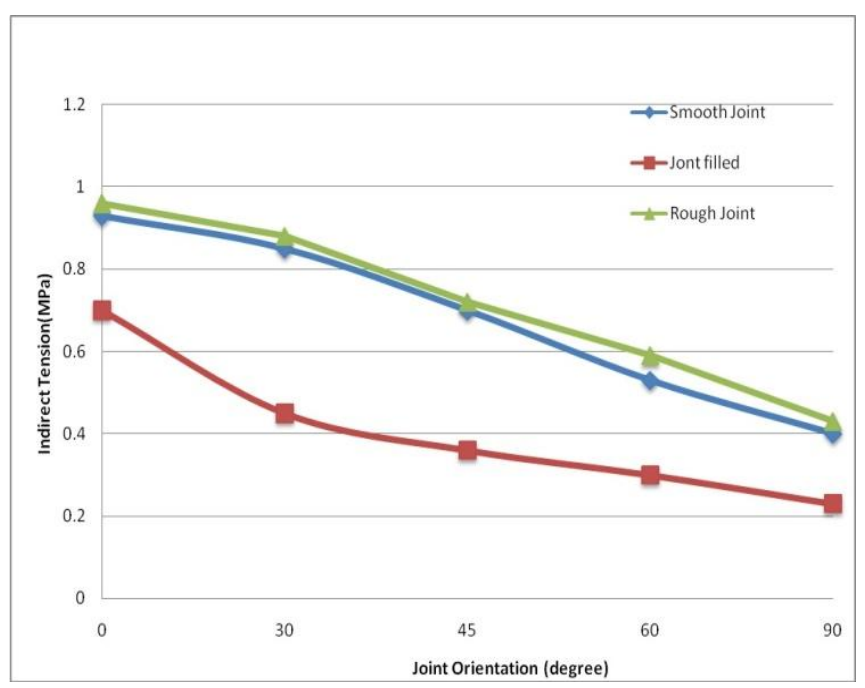

Fig -5: Relationship between Indirect tensile strength and joint orientation for Single Jointed Specimen

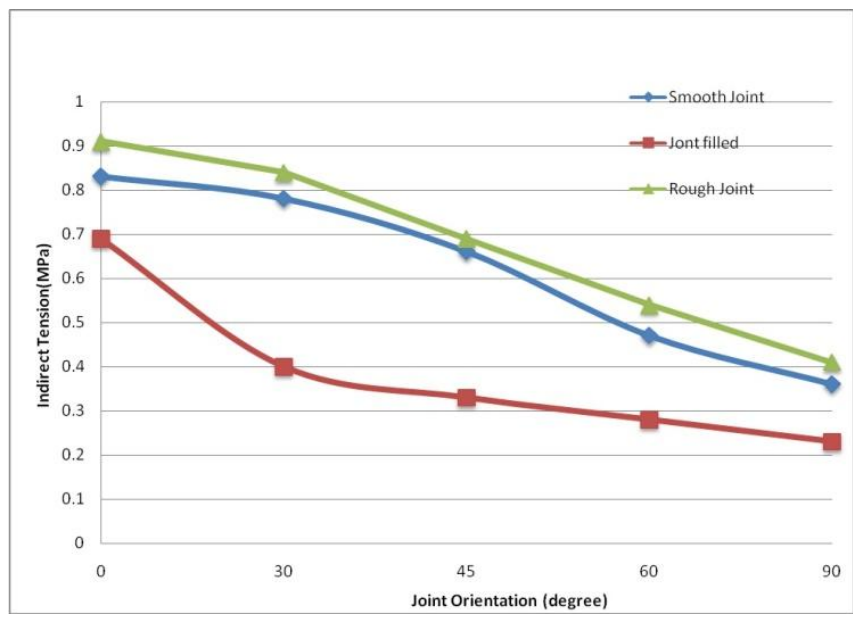

Fig -6: Relationship between Indirect tensile strength and joint orientation for Double Jointed Specimen

In joint condition, $0^{0}$ orientations shows higher tensile strength compared to other joint orientation. This behavior is may be because the direction of loading is perpendicular to joint orientation.

For the joint orientation at $90^{\circ}$, the specimen showed lesser value of indirect tension. This may be due to the loading direction is parallel to joint orientation.

\section{ANALYSIS OF UCS \& INDIRECT TENSION}

By plotting UCS against Indirect Tension it was found that there are two major groups showing distinct trend [Figure 7]. The two rock groups identified are listed in Table 2 . The correlation equations for Group A jointed rocks and Group $\mathrm{B}$ jointed rocks are given below as equations 1 and 2 respectively.

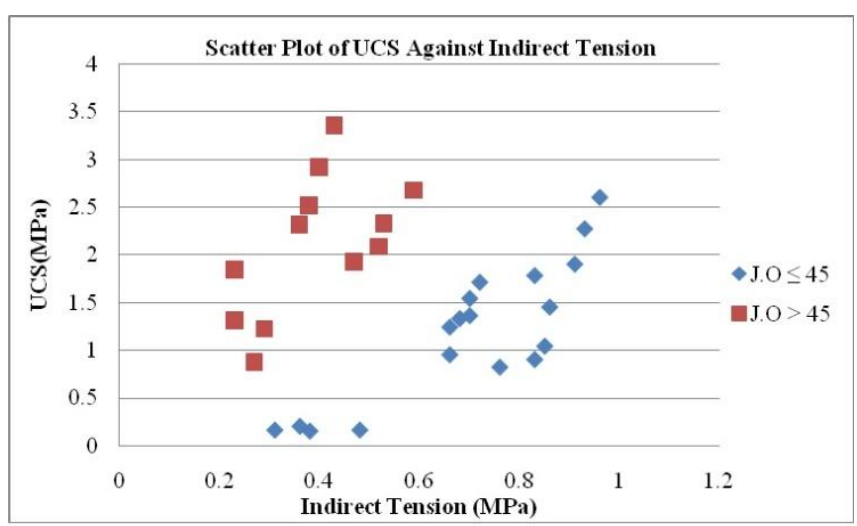

Fig -7: Scatter Plot of UCS against Indirect Tension for all the Tested Joint Rocks

Table -2: Jointed Rock Groups Identified by Scatter Plot of UCS and Indirect Tension

\begin{tabular}{|l|l|}
\hline Jointed Rock Group A & Jointed Rock Group B \\
\hline $\begin{array}{l}0^{\circ}, 30^{\circ} \text { and } 45^{\circ} \text { Joint } \\
\text { Orientation }\end{array}$ & $\begin{array}{l}60^{\circ} \text { and } 90^{\circ} \text { Joint } \\
\text { Orientation }\end{array}$ \\
\hline
\end{tabular}

$\mathrm{UCS}=2.45 \mathrm{I} . \mathrm{T}+0.45 \mathrm{~J} . \mathrm{C}-0.83 \quad \mathrm{~J} . \mathrm{O} \leq 45^{\circ}$ 
J.C - rough -1 , smooth -0.88 , filled -0.26

$\mathrm{UCS}=-1.56 \mathrm{I} . \mathrm{T}+3.28 \mathrm{~J} . \mathrm{C}-0.12 \quad \mathrm{~J} . \mathrm{O}>45^{\circ}$

J.C - rough -1 , smooth -0.9 , filled -0.49

Where,

UCS - Unconfined compressive strength

I.T - Indirect Tension Strength

J.C - Joint Condition

J.O - Joint Orientation

In Figure $8 \& 9$ we can check the accuracy of created equation $1 \& 2$.

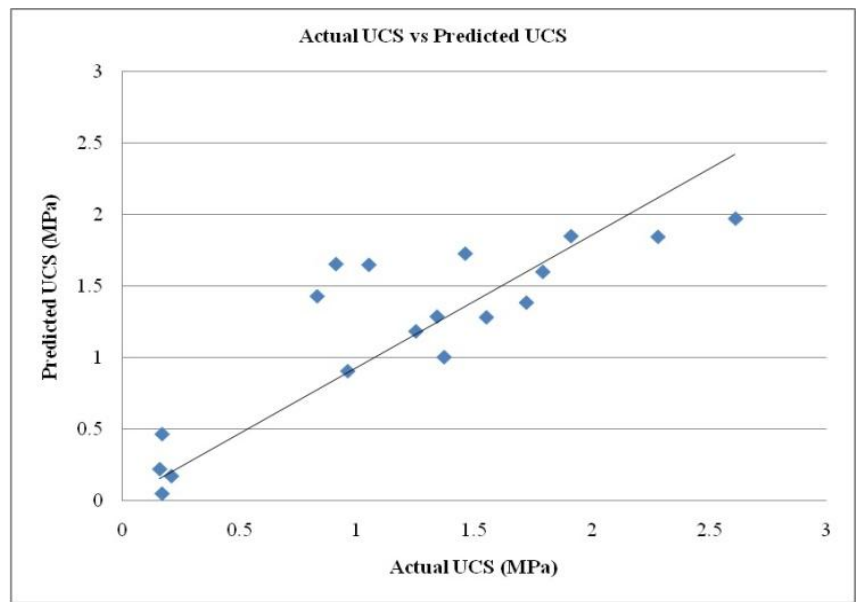

Fig -8: Predicted UCS vs Actual UCS for Jointed Rock Group A

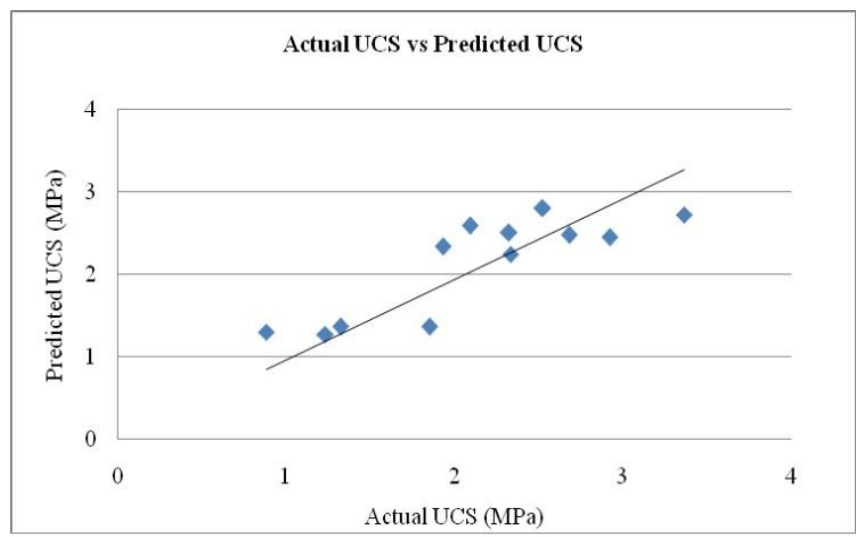

Fig -9: Predicted UCS vs Actual UCS for Jointed Rock Group B

From Figure $8 \& 9$ the closeness of predicted values to that of observed values could be seen clearly. It is noticed that except for the joint filled with clay and oriented at $30^{\circ}$, the deviation is minimum.

\section{REGRESSION STATISTICS}

Regression statistics for group A rock and group B rock are given detailed in the Table 3 \& Table 4. Generally the $\mathrm{R}$ square values ensure the strength of the derived equation. If the values of $\mathrm{R}$ square tend to 1 then the derived equation has the accurate value whereas $\mathrm{R}$ square values tend to 0 then the derived equation has the lower accuracy.
Table -3: Regression Statistics for J.O. $\leq 45^{\circ}$

\begin{tabular}{|l|l|l|}
\hline S.No & Name & Value \\
\hline 1 & Multiple R & 0.87 \\
\hline 2 & R square & 0.75 \\
\hline 3 & Adjusted R square & 0.72 \\
\hline 4 & Standard Error & 0.39 \\
\hline
\end{tabular}

Table -4: Regression Statistics for J.O. $>45^{\circ}$

\begin{tabular}{|l|l|l|}
\hline S.No & Name & Value \\
\hline 1 & Multiple R & 0.86 \\
\hline 2 & R square & 0.73 \\
\hline 3 & Adjusted R square & 0.67 \\
\hline 4 & Standard Error & 0.42 \\
\hline
\end{tabular}

\section{CONCLUSIONS}

The unconfined compressive strength tests and Indirect Tension tests were carried out on various joint orientations with different joint condition. Finally the equation relating both UCS \& Indirect Tension for jointed rocks are formed using Multiple Regression Analysis (SPSS Analyzing Tool) In future the equation can be formed by adopting various more joint conditions. By this we can predict the UCS value with more accurate using field indirect tension test.

\section{REFERENCES}

[1]. Farah. R [2011] Correlations Between Index Properties and Unconfined Compressive Strength of Weathered Ocala Limestone.UNF Theses and Dissertations.Paper 142.

[2]. N.Kabilan and M.Muthuraman [2015] Correlation between Uniaxial Compression strength and point load index for jointed rocks, International Journal of Earth Sciences and Engineering, Volume 8(2), 542-546.

[3]. Kahraman. S, Fener.M and Kozman.E [2012] Predicting the Compressive and Tensile Strength of Rocks from Indentation Hardness Index. Journal of the Southern African Institute of Mining and Metallurgy, 112(5), 331-339.

[4]. Altindag.R.and Guney.A [2010] Predicting the Relationships between Brittleness and Mechanical Properties(UCS,TS and SH) of Rocks.Scientific Research and Essay Vol.5(16),pp.2107-2118.

[5]. Akram.M, and Bakar M.Z.A [2007] Correlation between Uniaxial Compressive Strength And Point Load Index For Salt-Range Rocks. pak. J. Engg. \&Appl.Sci.Vol 1,pp 1-8.

[6]. Bieniawski.Z.T.[1975] Bulletin of Eng. Geol. Vol 9(1), pp 1-11. Broch.E, and Franklin.J [1972] J. Rock Mech. Min.Sci. Vol 9(6), pp 669-697.

[7]. Brown,E,T.[1985] Rock Characterization, Testing and Monitoring. ISRM Suggested Methods. Pergamon press, Oxford, pp 111-116. 
[8]. D. Andrea.D.V., Fischer.R.L and Fogelson.D.E [1964] US Department of the Interior, Bureau of Mines, Report of Investigations. Vol 6702, pp1-23.

[9]. Zuhair Kadhim Jahanger and Azad Abbas Ahmed [2013] Correlation Between Point Load Index and Very Low Uniaxil Compressive Strength of Some Iraqi Rocks. Australian Journal of Basic and Applied Sciences, Vol. 7, pp.216-229.

[10]. Mahendra Singh and Bhawani Singh. [2008], Laboratory and Numerical Modelling of a Jointed Rock Mass. The 12th international conference of international association for computer methods and advances in geomechanics, Vol 6, pp 1373-1380.

[11].Ramli Nazir.,Ehsan Momeni.,Danial Jahed Armaghani., \& Mohd For Mohd Amin.[2013] Correlations Between Unconfined Compressive Strength and Indirect Tensile Strength of Limestone Rock Samples.EJGE,Vol.18,pp 1737-1746.

[12]. Vekinis G, Ashby M.F and Beaumont W.R [1993], "Plaster of paris as a model material for brittle porous solids", Journal of material science, Vol.28, pp. 33213227.

\section{BIOGRAPHIES}

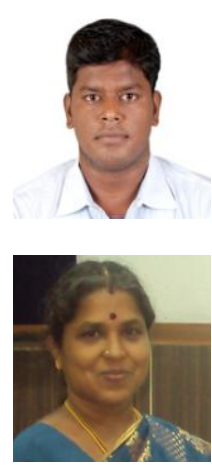

Former ME Soil Mechanics and Foundation Engineering from College of Engineering Guindy, Anna University Chennai, India

Professor, Department of Civil Engineering, College of Engineering Guindy, Anna University Chennai, India. 